\title{
FORMAL ACCOUNTING HARMONIZATION - A NEW MEASUREMENT SCHEME DEMONSTRATED BY VIETNAM'S DATA AND INTERNATIONAL FINANCIAL REPORTING STANDARDS
}

\author{
LE VU NGOC THANH \\ University of Economics Ho Chi Minh City - thanhlvn@ueh.edu.vn \\ HOANG TRONG HIEP \\ University of Economics Ho Chi Minh City - hoangtronghiep@ueh.edu.vn \\ (Received: January 11, 2017; Revised: March 24, 2017; Accepted: April 10, 2017)
}

\begin{abstract}
We are living in a "flat world" of international integration and adaptive trends. This requires countries to integrate their own regulations to those from other countries. Accounting regulations are no exception. It is necessary to measure how much a nation's accounting regulations are the same or different from those of another country or from International Financial Reporting Standards (IFRS).

Extant literature reveals a rich discussion about this topic. Many measurement schemes have been initiated and employed. However, it is argued that data classification processes in those works contain some flaws. This paper contends the data specifically used to evaluate accounting measurement issues. The data will be divided into initial and subsequent recognition because such partition collectively affects the financial report figures. Therefore, the similarity of accounting regulations as a whole should be the multiplication of initial and subsequent recognition similar degree. To this extend, this work contributes to the research theme.
\end{abstract}

Keywords: accounting; harmonization; convergence; Vietnam; IFRS.

\section{Introduction}

\section{Significance of this research}

The global integration of economies is obvious through the increasing number of countries participating in multinational FTAs and international organizations such as World Trade Organization, World Bank, and International Monetary Fund, etc. This creates institutional motivations for adjusting local economy to adapt others in terms of economic structures, elements in those structures and regulations underlined those structures (Irvine, 2008). Therefore, it is significant to investigate how much a nation's laws and economic regulations are similar to or different from those of other nations. Not only does this study demonstrate the global integration of economies, which probably helps enhance the globalization efforts, but it also shows existing differences. By removing those differences, the integration level could be enhanced.

For international accounting regulations, the International Accounting Standard Board (IASB) plays the key role in global accounting harmonization and convergence. This effort has been explicitly presented in their mission:

"Our mission is to develop IFRS Standards that bring transparency, accountability and efficiency to financial markets around the world." (IASB, 2016)

This mission supports the convergence process of international accounting because local authorities have to converge their national accounting regulations to make domestic rules become more transparent, 
accountable and effective.

Authors have paid much attention to measure and analyze the result of such effort. This paper is inspired by measuring the harmonization levels of accounting regulations. Extent literature review shows a nearly 4 - decade history first initiated by Van der Tas, (1988). He argued that academic work about this topic could be divided into two streams. One measures formal harmonization and the other measures material harmonization, respectively known as de jure and de facto harmonization. The first investigates accounting standards harmonization and the second focuses on financial reporting harmonization.

This research contends that literature about this topic is rich but needs improving, especially in measuring the harmonization degree of national accounting regulations. Previous key studies including those of Van der Tas, (1992); Rahman, et al., (1996); Garrido, et al., (2002); Rodrigues, et al., (2005) provide useful tools - such as Euclide's distances, Jaccard's coefficient, Spearman's correlation - for measuring the similarity and dissimilarity among regulations. These tools are helpful in calculating the degree of harmonization. However, we finds that there is a gap in the data classification and evaluation of these studies. This paper agrees with Rahman, et al. (ibid)'s viewpoint that measurement and disclosure are two distinct accounting issues. They are different in nature and have different influences on financial reporting. Therefore, we need to use different methods to evaluate them (Tay \& Parker, 1992). For example, disclosure harmonization degree could be acquired by using the same rules for the same accounting items. However, measurement harmonization degree needs to consider the impact of a measurement method on the final accounting figures in financial statements.

This research suggests that we should consider whether measurement issues used in regulations cover initial recognition or subsequent one. This is important because it will collectively result in the final accounting data for items in financial statements. Due to the chronological nature of two - step recognition, the effect accounting measurement rules (allowable methods, or allowable valuation scheme) will be measured by multiplying the impact of each step. Accordingly, the overall harmonization degree of an accounting item should be worked out by multiplying the similar degree in initial recognition with the degree in subsequent recognition.

This research also provides a more robust data collection scheme using available measurement methods or valuation schemes as comparing items. Previous studies either use standards by standards, rules by rules or principles by principles as comparing items. This will lead to a level of similarity between the two compared regulations in words other than in the impact of those regulations on financial statements.

\section{Research question}

From above gaps, this research aims to establish a more accurate and meaningful approach to measure the formal harmonization degree in accounting. Vietnam will be used as a case study to compare their regulations with IFRS to illustrate our points on new measuring scheme.

This research includes 3 sections. The first section provides basic information about harmonization, measurement in accounting and the research methodology used in this study. The second section emphasizes the measuring scheme, defining observation/ comparing items, and data collection/ evaluation in Vietnam setting. The final section shows the research results with further discussion.

\section{Theory and methodology}

Definition of harmonization

Harmonization is not a new scientific issue, at least in accounting. This term was 
firstly mentioned by Van der Tas, (1988) who said that 'harmonization is a co-ordination, a tuning of two or more subjects'.

Later discussions and studies made this definition clearer by distinguishing standardization from harmonization (Tay \& Parker, 1992). The former results the omission of options, while the latter is relating to clustering (e.g. of companies) around some choices (e.g. allowed accounting methods). Moreover, it should be noted that understanding the variation between compliance and harmonization is also vital. With the significant influence of IFRS, there is an obvious trend that nations seem not only adapt to but also comply with IFRS. Tay \& Parker, (1992), correlated this difference by distinguishing formal and material harmonization. They presumed that compliance with IFRS is formal harmonization. This research, however, agrees with Van der Tas, (1992), that formal harmonization is not totally similar to compliance. For example, both US GAAP and IFRS require many similar accounting regulations but they still have a lot of differences.

Harmonization is a state in which a certain degree of co-ordination exists between two or more subjects (Van der Tas, 1992). Harmonization measurement was simply concerned 'with the similarity or otherwise of accounting practices and regulations' (Tay \& Parker, 1992). Harmonization papers could be categorized in two main streams: formal harmonization (de jure) and material harmonization (de factor) (Van der Tas, 1992; Tay \& Parker, 1992). Formal harmonization relates to measuring the similar degree between regulations, whereas material harmonization measures the degree of clustering of companies around particular accounting methods.

Obviously, if material harmonization degree is high, which means companies use similar accounting options for similar transactions, events and conditions, the comparability of firms' financial information is theoretically high (Rahman, Perera, \& Ganeshanandam, 1996). There is evidence that 'material harmonization is an outcome of formal harmonization' (Rahman, Perera, \& Ganeshanandam, 1996). The level of formal harmonization could directly affect the comparability of financial information disclosed by firms.

Accounting measurement in harmonization

Measurement issue in accounting attracts much attention from both academics and practitioners (Rahman, Perera, \& Ganeshanandam, 1996). In accounting standards, measurement requirements account for major part, even more significant than disclosure requirements. Moreover, in correlation with disclosure, measurement matter contains different characteristic. Firstly, it is less discretional than its counterpart. In accounting standards, disclosure means requirements for information presentation. Some information is so essential that it is compulsorily presented while some other is regarded as supplemental or optional. Measurement issue is less discretional than disclosure issue. Accountants are only allowed to choose from a list of accepted accounting methods to measure accounting elements. Secondly, disclosure requirements seem different from one another while measurement requirements cluster around some acceptable practices. These differences necessitate a different approach to measure the harmonization level of measurement matter from those used for disclosure.

According to IFRS's conceptual framework, there are four fundamental accounting elements including asset, liability, income, and expense. Financial reporting is a translating process, in which accounting transactions, conditions and events are classified and transferred into financial statements via fundamental elements (Van der Tas, Measuring Harmonization of Financial Reporting Practice, 1988). In other words, 
accountancy's responsibility is to reflect operational activities into numbers and information as true and fair as possible. Measurement matter covers the way for weighing accounting elements. Mainly reviewing current effective IFRSs, this study finds that six value schemes and eight measuring methods can be used to calculate the amount of accounting elements presented in financial statements. It is unable to tell which measurement method is more significant than others provided that all of them are allowed. Thus the incorporation of important level of measurement approaches is unnecessary in research (Tay \& Parker, 1992). This could result in subjectivity and consequently distorts the research result.

Finally, an accounting element is first recognized when they incurred. Then, according to their classification (e.g. assets or liabilities), they will be adjusted or remeasured via selected measurement methods. These two step of recognition will collectively result in accounting numbers in financial statements. Therefore, when evaluating the harmonization of two regulations relating to an accounting element, it is necessary to separate between its initial recognition and subsequent recognition.

Thus, it is essential to use a separate approach to evaluate the harmonization degree of measurement issues. This approach must include the following characteristics

(1) All value schemes and measuring methods are of equal importance;

(2) Value schemes and measuring methods are the main fundamentals for comparing accounting items; and

(3) Finally, initial recognition and subsequent recognition must be separated.

\section{Methodology}

The two streams of harmonization research require different measuring schemes. However, they imply the same methodology which belongs to positivist paradigm, as this kind of research tries to acknowledge human through social facts (Paul, Hans, \& Jan, 1999). The facts mentioned in this study are principles in accounting standards or methods applied by companies.

\section{Research method}

\section{Measuring scheme}

Instant literature reveals various methods to evaluate the correlation between two accounting regulations. This research perceives that different indexes have been used, such as Herfindahl Index (Van der Tas, 1988), C-Index (Van der Tas, 1992), I-Index Hermann and Thomas, (1995). However, these indexes are more suitable for measuring material harmonization than formal harmonization (Mustata, Matis, Bonaci, \& Strouhal, 2010).

The primitive idea of measuring formal harmonization degree is inspired by geometry. Researchers argue that the closer the two regulations are, the more similar they are. Garrido et al., (2002), for example, used Euclidian Distance. In a multi-dimensional space, each factor of point A (or B) is an accounting issue in country A (or B)'s GAAP. AB's length is the distance between two sets of accounting standards. This method is virtually useful when evaluating the harmonization level of two sets of accounting regulations. Additionally, the trend of harmonization is also reflected through the increase or decrease of the calculated distance. However, there are still some problems in these methods. Firstly, distances are absolute values, which neglect the qualitative extent (e.g. compulsory or optional) of compared items (Rodrigues, Fontes, \& Craig, 2005). Secondly, the mathematic character of distance is its value ranging from zero to indefinite. While zero can be inferred as totally different, Euclidian distance is a lack of 'totally similar' result (Mustata, Matis, Bonaci, \& Strouhal, 2010). In brief, Euclidian Distance is useful to evaluate the overall change in alternative accounting options in quantity, but not in quality extent (Rodrigues, 
Fontes, \& Craig, 2005).

To overcome such limitations of distance method and to measure the harmonization level of accounting regulations, a recent research employed association coefficients to evaluate the proportion of shared features between two sets of document. Rodrigues, Fontes, \& Craig, (2005), use Jaccard's Coefficients in two alternatives, with and without considering the qualitative extent of each accounting matter. To consider qualitative extent, accounting issues are classified as 'required', 'recommended', 'allowed' and 'not permitted', and measuring at different weights, e.g. $1,0.75,0.5,0$ respectively. Including these characters in calculation may appropriately reflect the degree of similarity. Jaccard's coefficients basically defined as follows:

$\operatorname{Sij}=a a+b+c \& D i j=b+c a+b+c$

In which $\mathrm{Sij}$ and $\mathrm{Dij}$ respectively represent the level of similarity and dissimilarity between the two sets of accounting standards/regulations. ' $b$ ' is the number of accounting options valid in set $i$ but not in set $\mathrm{j}$, while $\mathrm{c}$ is the number of accounting options valid in set $\mathrm{j}$ but not in set $j$. ' $a$ ' is the number of accounting options valid in both sets. Output of this measurement is a relative number, which is more sensitive and easier to describe in terms of proportion of similarity (or dissimilarity).

Another statistic formula also used by Rodrigues et al. (2005) was Spearman's correlation coefficient and formulated as below:

$$
\begin{gathered}
\mathrm{rs}=\mathrm{i}=1 \mathrm{nR}(\mathrm{NCi}) \mathrm{R}(\mathrm{ICi})-\mathrm{n}((\mathrm{n}+1) / 2) 2 \mathrm{i}=1 \mathrm{nR}(\mathrm{NCi}) 2- \\
\mathrm{n}((\mathrm{n}+1) / 2) 2 \mathrm{i}=1 \mathrm{nR}(\mathrm{ICi}) 2-\mathrm{n}((\mathrm{n}+1) / 2) 2
\end{gathered}
$$

Of which, $\mathrm{n}$ is the total number of accounting options; $\mathrm{R}(\mathrm{NCi})$ is the rank order of accounting option $i$ of national accounting standards, and $\mathrm{R}(\mathrm{ICi})$ is the rank order of accounting option $\mathrm{i}$ of international accounting standards. Accounting options are ranked as 1: required, 2: recommended, 3: Allowed, 4: Forbidden, 5: Not regulated. rs ranges from -1 to +1 . The closer to +1 the rs is, the more similar the two set of accounting standards are. Therefore, this calculation could ascertain the statistical significance of outputs generated by Jaccards' coefficient.

Jaccard's coefficients are currently used by many academics. However, the limitation of this formula fostered many attempts to make it more significant. Qu \& Guohua, (2010) developed coefficient method by adding fuzzy clustering algorithm after computing the coefficient values. Fuzzy clustering method seems prominent because it could yield a clustering matrix $(\mathrm{Qu} \&$ Guohua, (2010)), making findings more indicative and informative. However, it is obvious that fuzzy similarity method aims to gather items by ranking their representative value. Items satisfying numeric requirements are grouped together while other items are evaluated separately. This method creates a group of highest ranked items other than a group of most similar items. For this consensus, not only does fuzzy clustering method make this work become more complicated but it is also not as effective as being mentioned in the findings.

Arguing that Jaccards' coefficients could lead to a wrong convergence degree if previously-valid accounting options turn out to be invalid in both sets of accounting standards/regulations; Mustata et al., (2010) suggested Sokal and Sneath's coefficient to account for 'absence accounting treatment' in revised coefficients. Sokal and Sneath's coefficient is formulated as follows:

$$
\mathrm{SSij}=2(\mathrm{a}+\mathrm{d}) 2(\mathrm{a}+\mathrm{d})+\mathrm{b}+\mathrm{c}
$$

With $d$ as the number of absent accounting treatments. Taking absent factor into account, Sokal and Sneath's coefficient is expected to generate a more accurate output.

Sokal and Sneath's coefficient suggested by Mustata et al., (ibid), is appropriate when it takes absent feature into consideration. However, it is nothing but a Jaccard's Coefficient derivative. When Jaccard's 
coefficient is employed, 'unpermitted' accounting measurements share the same character as 'absent feature'. Moreover, it can be seen that both similar and absent accounting treatments are double-weighted. The weighting of characteristic is influenced by data characteristic and researcher's interest whereas Mustata et al., (ibid) do not explain which factors influencing the validity of SSij.

In summary, methods for measuring formal accounting convergence level have been continuously developing over time. Among those methods, Jaccard's coefficient is currently the most appropriate, particularly in calculating formal accounting harmonization degree. It is used with some innovation, such as fuzzy clustering by Qu \& Zhang, (2010), or 'double weighted' similarity by Mustata et al. (ibid). However, those innovations, as mentioned above, not only make the research more complicated but also biasedly analyze the research findings. This paper, therefore, uses original Jaccard's coefficient to measure the level of formal convergence between Vietnam accounting regulations and IFRSs. Elements of every compared accounting issues will be weighted as instructed in the next section.

\section{Observations}

This study determines the harmonization level by averaging the value of many observations (variables). Literature review provides two main options for observations including accounting standards (Rodrigues, et al., 2005; Qu \& Zhang, 2010; Pham, 2012), or accounting items (Rahman et al., 1996; Garrido, et al., 2002). It is clear that the former contain drawbacks. Firstly, the number of accounting standards issued by different bodies is different. Apart from the nonequivalence of two regulations, it could be the case of grouping option. Secondly, studies using accounting standards as comparing items often take IFRSs as the comparing subjects and reflect national accounting standards on IFRSs. This proceed is more related to measuring the compliance level of national accounting standards with IFRSs other than the harmonization level (Tay \& Parker, 1992).

This study employs the ideal of Rahman et al., (1996) and Garrido et al., (2002), to use accounting items as observations, which is considered as intermediary medium to compare two set of regulations. This method help avoid the aforesaid "compliance bias" and "grouping bias".

Previous studies used samples of accounting items to analyze the harmony degree. This could lead to invalid results (Rahman, Perera, \& Ganeshanandam, 1996) due to sample error. This research builds a comprehensive category of accounting items. This category includes all [measuring] accounting issues mentioned in two sets of regulations. The four fundamental accounting elements are divided into smaller items often seen in financial reporting. This study refers to the 28-item table of Rahman et al., (1996) and the 20-item table of Garrido et al., (2002) thoroughly reading IFRSs and Vietnam accounting regulations to outline the whole picture of accounting items. Moreover, descriptive comparison made by auditing firms is also utilized to consider this category. 36 regular accounting items in financial statements and accounting regulations are finalized. Among these items, some are covered by others (e.g. borrowing cost capitalization, foreign exchange transactions, function and presentation currency, equity method, acquiring method, consolidated method, impairment, subsequent event, changes in accounting policy, accounting estimate and errors). The remaining 27 items are shown in Table 1. 


\section{Table 1}

Accounting items

\begin{tabular}{|c|c|c|}
\hline No & Observation & Note \\
\hline 1 & Inventories & \\
\hline 2 & Tangible fixed assets & \\
\hline 3 & Intangible fixed assets & \\
\hline 4 & Investment properties & \\
\hline 5 & Financial lease assets & Subsequent measurement only \\
\hline 6 & $\begin{array}{l}\text { Non-current fixed asset held for sale or discontinued } \\
\text { operation }\end{array}$ & Subsequent measurement only \\
\hline 7 & Financial assets & \\
\hline 8 & Employee benefit assets & \\
\hline 9 & Deferred tax asset & \\
\hline 10 & Financial liability & \\
\hline 11 & Deferred tax liability & \\
\hline 12 & Financial lease liability & \\
\hline 13 & Employee benefit liability & Initial recognition only \\
\hline 14 & Liability incurred in equity transaction & \\
\hline 15 & Provision, contingent liability & \\
\hline 16 & Revenue & Initial recognition only \\
\hline 17 & Borrowing cost & Initial recognition only \\
\hline 18 & Goodwill & \\
\hline 19 & Joint venture & Subsequent measurement only \\
\hline 20 & Investment after losing controlling power & Subsequent measurement only \\
\hline 21 & Investment in subsidiaries - Separate statement & \\
\hline 22 & Investment in associates - Separate statement & \\
\hline 23 & Investment in joint ventures - Separate statement & \\
\hline 24 & Investment in subsidiaries - Consolidated statement & \\
\hline 25 & Investment in associates - Consolidated statement & \\
\hline 26 & Investment in joint ventures - Consolidated statement & \\
\hline 27 & Non-control interest & \\
\hline
\end{tabular}


This study argues that accounting data presented in financial statements are affected by either initial or subsequent recognition; or both of them. Therefore, each accounting item is divided into two sub-items: initial recognition and subsequent recognition. For each sub-item, accounting requirements available in each regulation will be compared, making them as the lowest comparing level.

\section{Data}

Data sources

Most studies about formal harmonization often use accounting standards and other regulations (stock exchange listing rules) as data sources (Rahman, Perera, \& Ganeshanandam, 1996). Depending on each national context, different accounting regulations have diverse strengths. In Vietnam, accounting standards obviously function as general principles while Unified Accounting Guidelines (UAG) have a stronger legal enforcement (Pham, 2012). This study uses both regulations as data sources - IFRSs effective from June 2016 and Vietnam accounting regulations such as VASs, Decree 200/2014, Decree 202/2014, and Decree 210/2009 as data resources. These regulations contain disclosure and measurement requirements for financial reporting. Previous papers show that disclosure and measurement harmonization require different research approaches. This research only focuses on measurement matter which has been attracted much criticism (Rahman, Perera, \& Ganeshanandam, 1996) due to its significance.

\section{Data collection}

To avoid subjectivity in data collection, this research defines a clear process for filling the data in the comparing accounting items. Firstly, we picked out allowable measurements for each accounting items. Secondly, we classified them into initial recognition or subsequent recognition. Each variable is just considered once to avoid duplication. For example, goodwill is mentioned in Item 18, 21, and 23, one information is considered once. The rule of thumb is 'substance over form'. For example, goodwill and its measuring method will be considered once in Item 18. As the outcome of this measurement approach is the goodwill amount on balance sheet.

It is controversial for more than a decade that UAG is expected to integrate more with IFRSs than with VASs. This research also recognizes some dissimilarities and even conflicts between new UAG and VAS. Accordingly, information comparison between UAG and VAS is also recorded to provide indications for accounting standards improvement in Vietnam.

\section{Data evaluation}

This research does not comment on the effectiveness of each accounting method (Tay \& Parker, 1992) to avoid strange and bias outcome. Previous studies often use a typology of "required, recommended or suggested and allowed" to evaluate comparing items. Ranking accounting methods as required, recommended or suggested and allowed will not only result in inaccurate results but also create subjectivity. Also, there is lack of evidence in accounting standards about whether an accounting treatment is required, recommended or suggested. Only direct Cash Flow reporting method is found as preferable in IAS 7. Moreover, even if regulations say "required, recommended or suggested", this does not much affect the usage of any measurement methods. But the intention and style of management will decide which method should be used. Therefore, accounting number is less likely affected by this typology. This research uses two options 'allowed' and 'disallowed' to reflect the nature of requirements. If a measurement approach is either allowed or disallowed by both regulations, it will be marked as 1 , totally similar. Otherwise, it will be marked as 0 , totally dissimilar. Each subitem (e.g. initial recognition and subsequent recognition) will be evaluated by averaging all the comparing items inside. 
It is argued that accounting numbers are affected by initial and subsequent recognition. An accounting measurement requirement belongs to former or latter category depending on its chronological substance. According to probability rule, the overall probability of an event is calculated by multiplying the probability of its sub-events, which are sequent in a series of time. The overall similarity of each accounting items is also determined by multiplying the initial recognition's score by that of subsequent recognition. In case of revenue and expense, where initial recognition does not exist, it is assumed to be totally similar. This evaluating approach brings in a more meaningful result. Typically, the similarity of accounting regulations should reflect the similarity level of accounting figures in financial statements.

The average weighted method is thereafter used to measure the overall level of harmonization because each accounting item is as important as others. This fits the objective of financial reporting set out by IASB which is "financial reporting for general purpose".

\section{Results and Discussion \\ Results}

Research results in Table 2 shows a slow degree of formal accounting harmony between Vietnam accounting regulations and IFRS. Only 35\% accounting rules in both regulations lead to same accounting data for similar accounting events, transactions and conditions. This shows a negative result in the effort to converge national accounting regulations with international conventions, and disconfirm the results found by previous studies.

Seven accounting items are totally converged. These accounting items mainly relate to liabilities such as deferred tax liabilities, financial lease liabilities, and provision and contingent liabilities. Two accounting items relate to asset category such as financial lease assets and investments in joint venture. One item, the borrowing cost, relates to expense.

Revenue shows a harmonization degree of $80 \%$. Differences is reasoned by fair value evaluation of future benefit of revenue. For items such as non-current asset held for sales/ discontinuing operation, investment after losing controlling power, non-control interest, though both regulations have the same principles for initial recognition, only $50 \%$ of those are regarded as similar. Therefore, their overall convergent level is $50 \%$.

\section{Table 2}

Research findings

\begin{tabular}{|c|l|c|c|c|c|c|c|c|c|c|}
\hline \multirow{2}{*}{ No } & $\begin{array}{l}\text { Variables } \\
\text { (Accounting } \\
\text { items) }\end{array}$ & \multicolumn{2}{|l|}{ IFRS \& UAG } & \multicolumn{2}{l|}{ IFRS \& VAS } & \multicolumn{3}{l|}{ UAG \& VAS } \\
\cline { 2 - 12 } & Ini- & Sub- & Overall & Ini- & Sub- & Overall & Ini- & Sub- & Overall \\
\hline 1 & Inventories & 1.00 & 1.00 & $\mathbf{1 . 0 0}$ & 1.00 & 0.88 & $\mathbf{0 . 8 8}$ & 1.00 & 0.88 & $\mathbf{0 . 8 8}$ \\
\hline & $\begin{array}{l}\text { Tangible } \\
\text { fixed assets }\end{array}$ & 1.00 & $0-$ & - & 1.00 & - & - & 1.00 & 1.00 & $\mathbf{1 . 0 0}$ \\
\hline & $\begin{array}{l}\text { Intangible } \\
\text { fixed assets }\end{array}$ & 1.00 & - & - & 1.00 & - & - & 1.00 & 1.00 & $\mathbf{1 . 0 0}$ \\
\hline & $\begin{array}{l}\text { Investment } \\
\text { properties }\end{array}$ & 1.00 & - & - & 1.00 & - & - & 1.00 & 1.00 & $\mathbf{1 . 0 0}$ \\
\hline & $\begin{array}{l}\text { Financial } \\
\text { lease assets }\end{array}$ & 1.00 & 1.00 & $\mathbf{1 . 0 0}$ & 1.00 & 1.00 & $\mathbf{1 . 0 0}$ & 1.00 & 1.00 & $\mathbf{1 . 0 0}$ \\
\hline 6 & Non-current & 1.00 & 0.50 & $\mathbf{0 . 5 0}$ & 1.00 & 0.50 & $\mathbf{0 . 5 0}$ & 1.00 & 1.00 & $\mathbf{1 . 0 0}$ \\
\hline
\end{tabular}




\begin{tabular}{|c|c|c|c|c|c|c|c|c|c|c|}
\hline \multirow{2}{*}{ No } & \multirow{2}{*}{$\begin{array}{c}\text { Variables } \\
\text { (Accounting } \\
\text { items) }\end{array}$} & \multicolumn{3}{|c|}{ IFRS \& UAG } & \multicolumn{3}{|c|}{ IFRS \& VAS } & \multicolumn{3}{|c|}{ UAG \& VAS } \\
\hline & & Ini- & Sub- & Overall & Ini- & Sub- & Overall & Ini- & Sub- & Overall \\
\hline & $\begin{array}{l}\text { asset held for } \\
\text { sales/ } \\
\text { discontinuing } \\
\text { operation }\end{array}$ & & & & & & & & & \\
\hline 7 & $\begin{array}{l}\text { Financial } \\
\text { assets }\end{array}$ & 0.33 & - & - & - & - & - & 0.33 & 0.50 & 0.17 \\
\hline 8 & $\begin{array}{l}\text { Employee } \\
\text { benefit assets }\end{array}$ & - & - & - & - & - & - & 1.00 & 1.00 & 1.00 \\
\hline 9 & $\begin{array}{l}\text { Deferred tax } \\
\text { assets }\end{array}$ & 1.00 & - & - & 1.00 & 0.50 & 0.50 & 1.00 & - & - \\
\hline 10 & $\begin{array}{l}\text { Financial } \\
\text { debts }\end{array}$ & 0.50 & 0.17 & 0.08 & - & - & - & 0.50 & 0.67 & 0.33 \\
\hline 11 & $\begin{array}{l}\text { Deferred tax } \\
\text { liabilities }\end{array}$ & 1.00 & 1.00 & 1.00 & 1.00 & 1.00 & 1.00 & 1.00 & 1.00 & 1.00 \\
\hline 12 & $\begin{array}{l}\text { Financial } \\
\text { lease } \\
\text { liabilities }\end{array}$ & 1.00 & 1.00 & 1.00 & 1.00 & 1.00 & 1.00 & 1.00 & 1.00 & 1.00 \\
\hline 13 & $\begin{array}{l}\text { Employee } \\
\text { benefit } \\
\text { liabilities }\end{array}$ & 0.25 & 0.25 & 0.06 & - & - & - & 0.75 & 0.75 & 0.56 \\
\hline 14 & $\begin{array}{l}\text { Liabilities } \\
\text { from dividend } \\
\text { payment }\end{array}$ & 1.00 & - & - & 1.00 & - & - & 1.00 & 1.00 & 1.00 \\
\hline 15 & $\begin{array}{l}\text { Provision, } \\
\text { contingent } \\
\text { liability }\end{array}$ & 1.00 & 1.00 & 1.00 & 1.00 & 1.00 & 1.00 & 1.00 & 1.00 & 1.00 \\
\hline 16 & Revenue & 0.80 & N/A & 0.80 & 1.00 & N/A & 1.00 & 0.80 & N/A & 0.80 \\
\hline 17 & $\begin{array}{l}\text { Borrowing } \\
\text { cost }\end{array}$ & 1.00 & N/A & 1.00 & 1.00 & N/A & 1.00 & 1.00 & N/A & 1.00 \\
\hline 18 & Goodwill & - & - & - & - & - & - & 1.00 & - & - \\
\hline 19 & $\begin{array}{l}\text { Investments } \\
\text { in Joint } \\
\text { venture }\end{array}$ & 1.00 & 1.00 & 1.00 & 1.00 & 1.00 & 1.00 & 1.00 & 1.00 & 1.00 \\
\hline 20 & $\begin{array}{l}\text { Investment } \\
\text { after losing } \\
\text { controlling } \\
\text { power }\end{array}$ & 1.00 & 0.50 & 0.50 & 1.00 & - & - & 1.00 & 0.50 & 0.50 \\
\hline 21 & $\begin{array}{l}\text { Investment in } \\
\text { subsidiaries - } \\
\text { Separate } \\
\text { statement }\end{array}$ & - & 0.33 & - & - & 0.33 & - & 1.00 & 0.67 & 0.67 \\
\hline 22 & Investment in & - & 0.33 & - & - & 0.33 & - & 1.00 & 0.67 & 0.67 \\
\hline
\end{tabular}




\begin{tabular}{|c|c|c|c|c|c|c|c|c|c|c|}
\hline \multirow{2}{*}{ No } & \multirow{2}{*}{$\begin{array}{c}\text { Variables } \\
\text { (Accounting } \\
\text { items) }\end{array}$} & \multicolumn{3}{|c|}{ IFRS \& UAG } & \multicolumn{3}{|c|}{ IFRS \& VAS } & \multicolumn{3}{|c|}{ UAG \& VAS } \\
\hline & & Ini- & Sub- & Overall & Ini- & Sub- & Overall & Ini- & Sub- & Overall \\
\hline & $\begin{array}{l}\text { associates - } \\
\text { Separate } \\
\text { statement }\end{array}$ & & & & & & & & & \\
\hline 23 & $\begin{array}{l}\text { Investment in } \\
\text { joint ventures } \\
\text { - Separate } \\
\text { statement }\end{array}$ & - & 0.33 & - & - & 0.33 & - & 1.00 & 0.67 & 0.67 \\
\hline 24 & $\begin{array}{l}\text { Investment in } \\
\text { subsidiaries - } \\
\text { Consolidated } \\
\text { statement }\end{array}$ & - & 1.00 & - & - & 1.00 & - & 1.00 & 1.00 & 1.00 \\
\hline 25 & $\begin{array}{l}\text { Investment in } \\
\text { associates - } \\
\text { Consolidated } \\
\text { statement }\end{array}$ & - & - & - & - & - & - & 1.00 & 1.00 & 1.00 \\
\hline 26 & $\begin{array}{l}\text { Investment in } \\
\text { joint ventures } \\
- \\
\text { Consolidated } \\
\text { statement }\end{array}$ & - & - & - & - & - & - & 1.00 & 1.00 & 1.00 \\
\hline 27 & $\begin{array}{l}\text { Non-control } \\
\text { interest }\end{array}$ & 0.50 & 1.00 & 0.50 & 0.50 & 0.50 & 0.25 & 1.00 & 0.50 & 0.50 \\
\hline \multicolumn{2}{|c|}{ Overall results } & 0.61 & 0.42 & 0.35 & 0.57 & 0.38 & 0.34 & 0.94 & 0.79 & 0.77 \\
\hline \multicolumn{2}{|c|}{$\begin{array}{l}\text { Note: Ini - Initial } \\
\text { recognition; Sub-: } \\
\text { subsequent } \\
\text { recognition }\end{array}$} & & & & & & & & & \\
\hline
\end{tabular}

Other items are recorded as mostly divergent. These items could be divided into 3 groups: (1) items diverging in initial recognition, (2) items diverging in subsequent recognition, and (3) items diverging in both initial and subsequent recognition. The first group relates to investments in associates, joint ventures and subsidiaries in separate financial statements. For initial record of these items in financial statements, UAG requires that costs such as legal fees, commission for dealer must be included in costs of those investments while in IFRSs (IAS 27 and IFRS 3) such costs are excluded. The difference in subsequent recognition existing in these items are interesting. To record these items, accountants can use historical cost method, equity method or fair value method. Both regulations allow to use the first method but only IFRS allows the latter two. This study is aware of the fact that VAS does not mention equity method but UAG does. Whereas, UAG provisions do not allow impairment recognized while IAS 27 does. Moreover, IFRS 9 also stated that these accounting items could be considered as equity instruments, thus could be recognized at fail value.

The second group includes tangible fixed assets, intangible fixed assets, investment properties, deferred tax assets, financial 
assets, and liabilities from dividend payment. According to IFRS, impairment is allowed if those assets are recorded via historical cost model. Fair value valuation is allowed if those assets are recorded via revaluation model. These provisions are not allowed by UAG. It is also true for liabilities from dividend payment, which must be re-evaluated annually according to changes in its fair value.

The third group presents items diverging in both initial and subsequent recognition. This includes employee benefit assets, goodwill, and investment in associate and joint venture in consolidated financial statements. Goodwill in both regulations requires that acquisition method must be employed. But the application of this method is varied. In terms of investments in consolidated financial statements, impairment is the main force making the regulations diverging. Employee benefit asset is a different case when UAG does not use any provision for this item.

This research also finds that Vietnam authority has made some efforts to integrate IFRS into the national accounting regulations. $33 \%$ of accounting principles has been improved. However, the actual impact of these innovation on harmonization degree is inconsiderable taking up from $34 \%$ to $35 \%$. These findings affect the de factor harmonization in accounting of Vietnam enterprises with those employed IFRSs.
Consequently, the comparability of accounting numbers is still weak.

\section{Discussion}

It could be said that assets valuation is the main force making Vietnam accounting regulation diverging from international convention and practices. Further investigation made on diverging accounting items, this study finds three main reasons why the two regulations diverge. First, IFRS allows to use fair value in revaluation model to measure assets after initial recognition, acquisition method and equity method to measure investments in subsidiaries, associates and joint ventures. Second, the application of measuring method is different. This explains the variety in the measurement for investment for equity instrument, noncontrolling interest and goodwill. Third, there is a lack of provisions for items such as employee benefit and financial instruments.

\section{Conclusion}

The findings show the similarity level of Vietnam accounting regulation, calculated by considering both initial and subsequent recognition, is much lower than previous data collection schemes because initial and subsequent recognition collectively affect accounting numbers in financial statements. The new approach is more appropriate to compare accounting regulations. This raises the question about validity of previous research in the theme

\section{References}

Brown, P. (2011). International Financial standards: What are the benefits? Acccounting and Business Research, 41(3), 269-285.

Garrido, P., León, Á., \& Zorio, A. (2002). Measurement of formal harmonization progress: The IASC experience. International Journal of Accounting, 37(1), 1-26.

IASB. (2016). Mission statement. Retrieved from http://www.ifrs.org/About-us/Pages/IFRS-Foundation-andIASB.aspx

Mustata, R. V., Matis, D., Bonaci, C. G., \& Strouhal, J. (2010). Econometric tools Used in Measuring Accounting Harmonization: A Necessity Imposed Through Globalization. The 5th WSEAS International Conference on Economy and Management Transformation. Timisoara, Romania: West University of Timisoara.

Paul, P., Hans, K., \& Jan, K. (1999). Doing a Research in Political Science: An introduction to comparative methods and statistics (1st ed.). London: SAGE Publications. 
Pham, H. H. (2012). A comparative study of Vietnamese and international accounting standards. Ph.D paper. Retrieved from http://espace.library.curtin.edu.au/R?func=dbin-jump-full\&local_base=gen01era02\&object_id=192069

Rahman, A., Perera, H., \& Ganeshanandam, S. (1996). Measurement of Formal Harmonization in Accounting: An Exploratory Study. Accounting and Business Research, 26(4), 325-339.

Rodrigues, L. L., Fontes, A., \& Craig, R. (2005). Measuring convergence of National Accounting Standards with International Financial Reporting Standards. Accounting Forum, 29, 415 - 436.

Tay, J., \& Parker, R. (1992). Measuring International Harmonization and Standardization: A Reply. Abacus, 28(2).

Van der Tas, L. G. (1988). Measuring Harmonization of Financial Reporting Practice. Accounting and Business Research, 18(70), 157-169.

Van der Tas, L. G. (1992). Evidence of EC financial reporting practice harmonization: The case of deferred taxation. European Accounting Review, 1(1), 69-104.

Irvine, H. (2008). The global instituationalization of financial reporting: The case of the United Arab Emirates. Accounting Forum, 125-142. 